\title{
A study on effects of ceramic foam filter on flow aspect through water modeling experiment
}

\author{
*Ho-Young Hwang ${ }^{1,2}$, Cheol-Hee Nam ${ }^{3}$, Young-Sim Choi', Jun-Ho Hong', Xun Sun ${ }^{4}$ \\ 1. Cyber Manufacturing Process Group, Korea Institute of Industrial Technology, Incheon, 21999, South Korea \\ 2. Department of Robotics and Virtual Engineering, Korea University of Science and Technology, Daejeon, 34113, South Korea \\ 3. Materials Science and Engineering, Kyoto University, Kyoto 606-8501 Japan \\ 4. Shenyang Research Institute of Foundry, Shenyang 110022, China
}

\begin{abstract}
Casting defects that are closely related to entrapped air bubbles and metallic oxides occur very frequently in the sand mold casting process. Many researchers have shown that these defects can be reduced by adopting an appropriate gating system design. However, it is difficult for field engineers to identify a specific gating system that is more appropriate for their products. In this study, we tried to draw a comparison between two gating system designs with and without a ceramic foam filter. The ceramic foam filter was added to the horizontal runner just after the down sprue to prevent air bubble generation and reduce turbulence without a change of gating system design. The water modeling experiment was conducted with four different amounts of the initial volumes of water in the reservoir to verify the effects of initial pouring velocity. The results of the experiment applying the filter showed remarkably changed flow characteristics. The use of the filter was found to convert the flow pattern of water in the desired direction. The ceramic foam filter performed well to reduce flow velocity and stabilize the water stream. The flow pattern without a filter can be improved significantly even with the the use of just a 10 PPI irregular filter. Although the study confirmed that use of the filter may change the flow characteristics, it needs to be noted that the use of the ceramic filter alone cannot solve all the problems caused by a poorly designed gating system.
\end{abstract}

Key words: ceramic foam filter; sprue; gating system design; sand mold casting; casting defect

CLC numbers: TG242/TP391.9 Document code:A Article ID: 1672-6421(2017)03-216-10

$\mathrm{T}$ The gravity casting process has a long history and it has seen significant technological advances through the ages. However, many kinds of defects still remain to be solved since there are various factors to be considered to produce a sound casting. In addition, it is not easy to find a solution to these problems because casting is accompanied by complex symptoms.

Under a poor gating design, many defects such as shrinkage, gas porosity, oxide inclusions, misrun, etc. easily occur during the pouring step ${ }^{[1]}$. Gas porosity appears to be a common defect related to general gravity casting. The issue of gas porosity is very hazardous because it can reduce the strength of the casting product ${ }^{[2,3]}$. It has been reported that metallic oxides of the nonferrous alloy are mainly generated by the overlapping of oxidized layers on the surface of molten metal. The overlapping of the oxidized layer occurs due

\section{*Ho-Young Hwang}

Male, born in 1964, Ph. D and Professor. His research interests mainly focus on the numerical simulation of mold filling and solidification, and optimal gating system design.

E-mail: hyhwang@kitech.re.kr

Received: 2016-10-09; Accepted: 2017-02-11 to backflow in a runner or free surface sloshing in the mold cavity. This defect undermines the casting quality by appearing on the surface as oxide film layers ${ }^{[4-}$ 6]. To date, many studies have been conducted to find techniques that can reduce the defects arising from air bubbles and oxide intrusion in molten metal. Kuritama et al. proved the influence of pouring velocity in gravity casting by showing differences in the quality of casting at each velocity ${ }^{[7]}$. Masoumi M and Hsu Fu-yan showed that improvement could be achieved by redesigning the gating system without a pouring velocity decrease. They minimized the resistance of the water stream with curved waterways ${ }^{[8,9]}$. Campbell $\mathrm{J}$ investigated the specific principles underlying the process of defect occurrence in the pouring procedure. These researchers were able to identify the factors of a well-designed gating system that can reduce the defects that occur during the procedure of pouring molten metal ${ }^{[10-13]}$.

In the foundry, it is difficult to prevent the generation of impurities during the casting process. This causes significant defects in castings. For these reasons, ceramic foam filters are mainly used to prevent the inflow of impurities. There has been much research about the role of these filters ${ }^{[14,15]}$. However, besides 
these points, this study focuses on preventing the generation of turbulent flow. Casting quality can be improved by enhanced flow stability as the molten metal flow passes through the porous filter. Filters can turn the turbulent flow to laminar flow alongside decreasing flow velocity. These uses of the filter were proved by casting experiments and filter simulations ${ }^{[16-18]}$. There are also some studies that investigate the characteristics and functions of ceramic foam filters. In these studies, the researchers tried to obtain generalized principles about the filter along with experimental measurement data ${ }^{[19-22]}$.

In this study, we attempted to compare the difference in flow aspect according to the type of filters when the filter is installed in the gating system. Thereafter, we examined to what extent the filter can stabilize the flow of water without changing the gating system.

\section{Experimental procedure}

Reynolds number defines the dynamic characteristics of fluid flow. Even when two models are the same shape but different sizes and the fluid flowing inside the model is different from the other, a similarity can be observed between the two models if the scaling ratio between the two models is same and Reynolds number is the same. The kinematic viscosity of water at $20^{\circ} \mathrm{C}$ is $0.01 \mathrm{~m}^{2} \cdot \mathrm{s}^{-1}$ and the kinematic viscosity of molten $\mathrm{Al}$ alloy is $0.00959 \mathrm{~m}^{2} \cdot \mathrm{s}^{-1}$. Both values are quite similar. If we use the experimental model of the same shape and size and water is used as the fluid, the water flow is expected to represent the real casting process for aluminum alloy at a reasonable level of similarity. Therefore, in this study, the water model experiment was used instead of the actual casting experiment to investigate the internal flow in the casting process.

In general, when fluid is flowing through the interior of a complicated shape, pressure loss occurs and the velocity of the fluid decreases. Therefore, the flow patterns of the runner and gate are very likely to be affected by the internal shape of the cavity. Therefore, a simple rectangular shape was selected as an experimental casting model in order to observe the effect of the presence of the ceramic filter on the change in the flow pattern of the gating system.

The traditional gating system is shown in Fig. 1. This traditional gating system has been widely used in current foundry workplaces. The
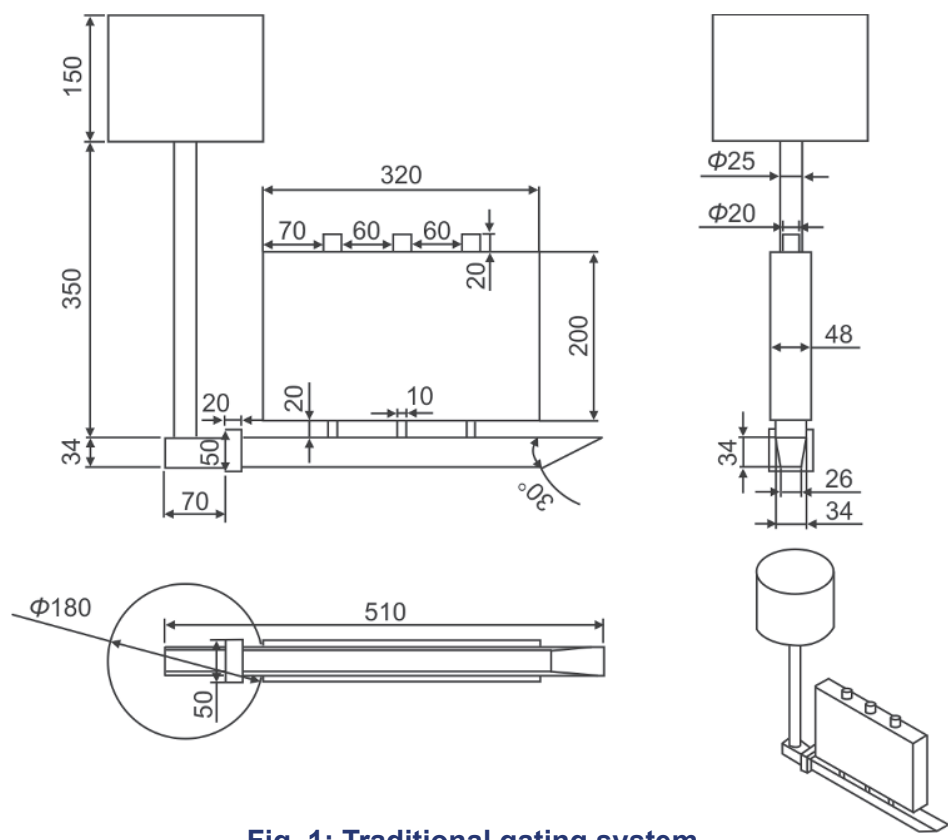

Fig. 1: Traditional gating system

gating system consists of one down sprue of circular cross-section, one runner of trapezoidal cross-section and three gates of rectangular cross-section. In addition, for smooth filling of water for the water model experiment, three vents of circular cross-section were added on the top of the casting. In order to recreate the similar pouring condition repeatedly, a water reservoir with stopper was added on top of the down sprue.

The flow-adaptive gating system was designed to minimize flow resistance in the down sprue and runner. The main purpose of this gating system is to reduce casting defects related to air bubbles and oxide inclusions. A drawing of this gating system is shown in Fig. 2. It consists of one down sprue of rectangular cross-section, one runner of trapezoidal cross-section and three gates of rectangular cross-section. The draft angle of the down sprue is about 0.7 degrees and the runner has a wider width and smaller height than the traditional gating system. Three air vents were installed at the top of the casting for a smooth filling
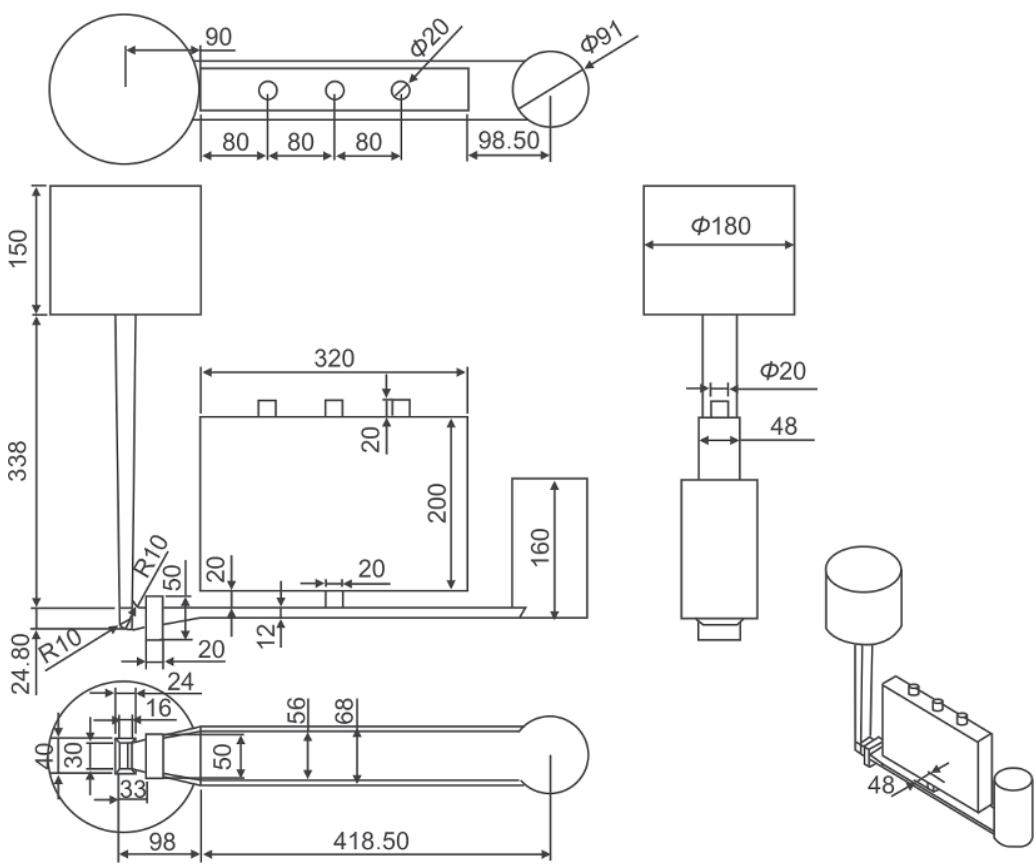

Fig. 2: Flow adaptive gating system 
as in the traditional gating system. Additionally, a blind feeder was added at the end of the runner to eliminate the impurities that are frequently found in the initial pouring stage. Other shapes are exactly the same as the traditional gating system.

In this study, three kinds of irregular filters (10 PPI, 20 PPI, $30 \mathrm{PPI})$ and a regular filter (10 PPI) were used as shown in Fig. 3 . The PPI refers to the number of pores per one square inch. In order to compare the differences using and not using filters, the filter was installed in the runner near the down sprue, as shown in Fig. 1 and Fig. 2. All other conditions are the same with the experiment without a filter. In general, the chemical composition of the ceramic foam filter is $52 \%-55 \% \mathrm{SiO}_{2}$ and $38 \%-41 \%$ $\mathrm{Al}_{2} \mathrm{O}_{3}$ according to the type of filter and company. The filter can be used up to $1,500{ }^{\circ} \mathrm{C}$ for the cast iron or ductile cast iron, up to $1,740{ }^{\circ} \mathrm{C}$ for cast steel and $850{ }^{\circ} \mathrm{C}$ for aluminum alloys. The range of mass flow rate is $1-6 \mathrm{~kg} \bullet \mathrm{s}^{-1}$.

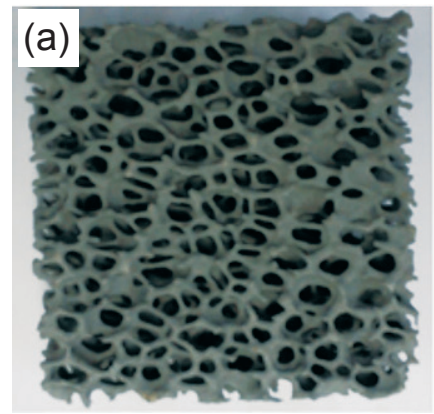

(a) Irregular $10 \mathrm{PPI}$

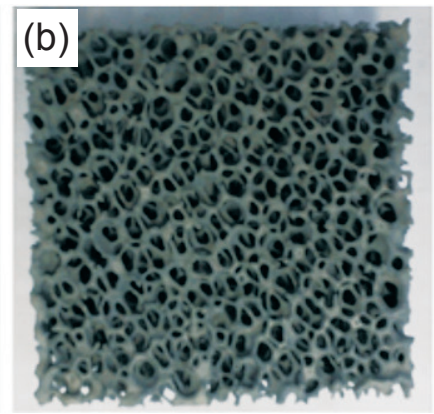

(b) Irregular $20 \mathrm{PPI}$

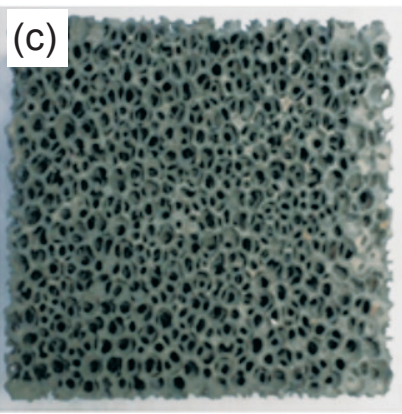

(c) Irregular $30 \mathrm{PPI}$

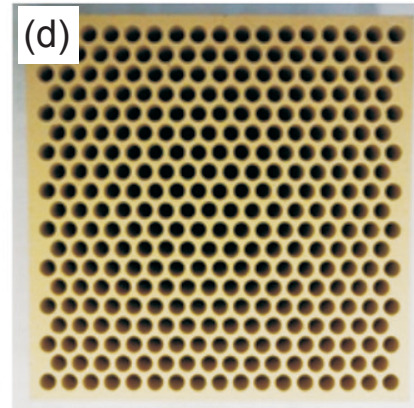

(d) Regular $10 \mathrm{PPI}$

Fig. 3: Ceramic foam filters for experiment

Both experimental models were made of transparent acrylic material. In order to enhance visibility, the water used in the experiment was tinted blue. Experimental equipment was set as in Fig. 4 and two Photron's high-speed cameras and video recording software were used to record the internal flow pattern. The video recording speed of high-speed cameras was $500 \mathrm{fps}$ (frames per second). The resolution of the first camera was $512 \times 512$ and the second camera was $512 \times 256$. The first camera was used to record the entire region and the second camera was used to particularly record the flow in the area where the filter is installed. Each case of the experiment was repeated over 10 times in order to confirm consistent results.
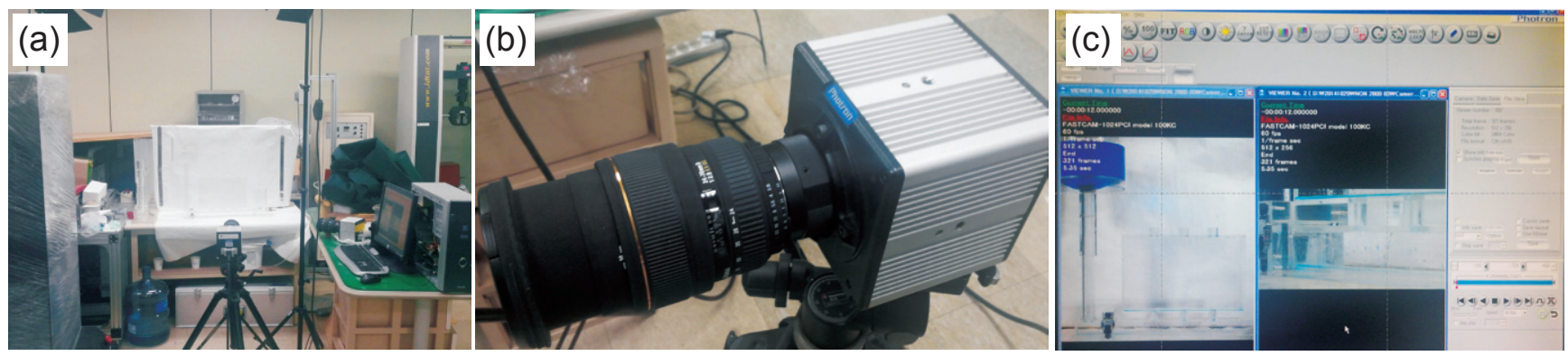

Fig. 4: Equipment for water model experiment

\section{Results and discussion}

\subsection{Traditional gating system}

The results of the water model experiment when the filter is not installed and the initial water volume of the pouring reservoir is $1,600 \mathrm{ml}$ are presented in Fig. 5. After $0.24 \mathrm{~s}$ from the pouring start, the waterfall meets with the bottom of the runner and spatters dispersedly. As shown at $0.36 \mathrm{~s}$, the water flow in the runner is close to the turbulent flow with lots of blobs and bubbles because of the high water flow speed and the collision between blobs which are reflected on the runner planes. At $0.54 \mathrm{~s}$, water flow reaches the end of the runner and changes its direction toward the down sprue. During this procedure, water flow overlaps with backflow and makes swirls in the runner at $0.63 \mathrm{~s}$. After this, the water flows into the casting part through the gate at $0.82 \mathrm{~s}$. The casting part is filled beginning from the gate located at the end of the runner and the filling takes place in the order of proximity to the end of the runner. The water past the right gate has the highest height, the water past the middle gate is the second highest, and the water past the left gate has the lowest height. The above phenomenon is due to the pressure difference before and after the gates and for that reason, the velocities at the gates have a large difference. This in turn generates free surface fluctuation. Thereafter, the sloshing of the free surface in the casting part becomes smaller after the filling process ends.

Figure 6 shows the results of the water model experiment when the filter is not installed and the initial water volumes of the reservoir are 2,000 $\mathrm{ml}, 2,400 \mathrm{ml}$, and 2,800 $\mathrm{ml}$ in each. The overall aspects of water flow are almost similar to the experiment with an initial pouring volume of 1,600 $\mathrm{ml}$. Before the moments of water flowing to the inside of the casting part, filling processes are a little faster than the case of $1,600 \mathrm{ml}$ due to the high flow 


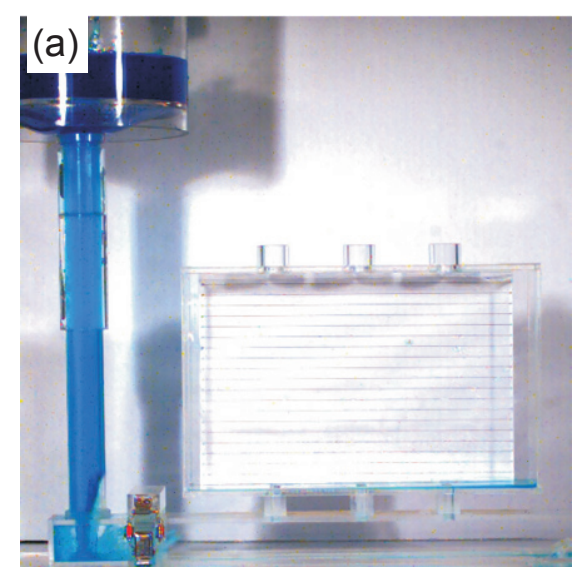

(a) $0.24 \mathrm{~s}$

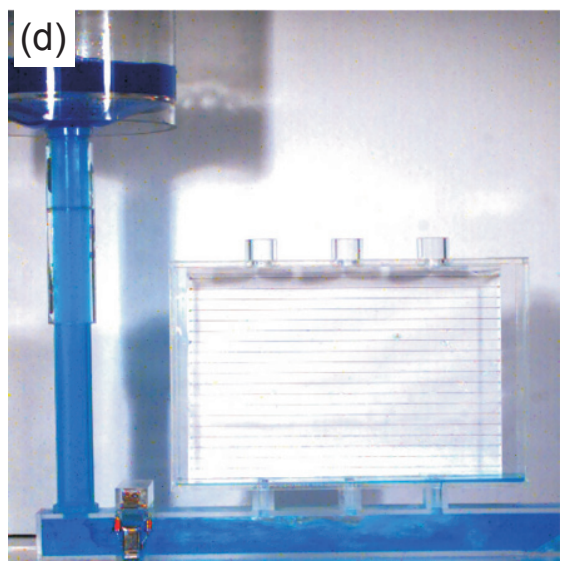

(d) $0.63 \mathrm{~s}$

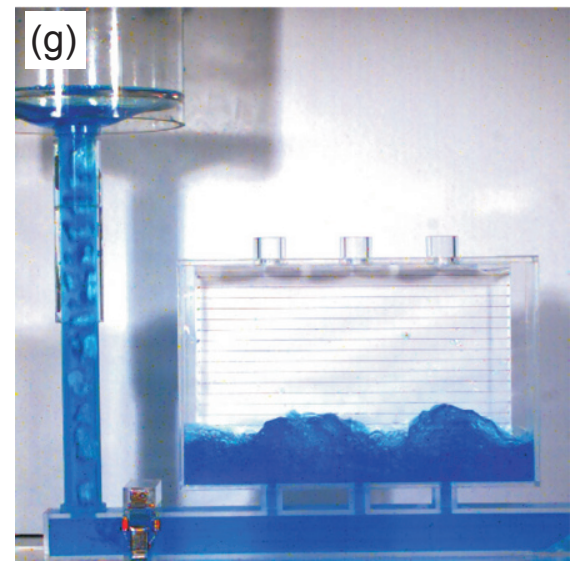

(g) $1.64 \mathrm{~s}$

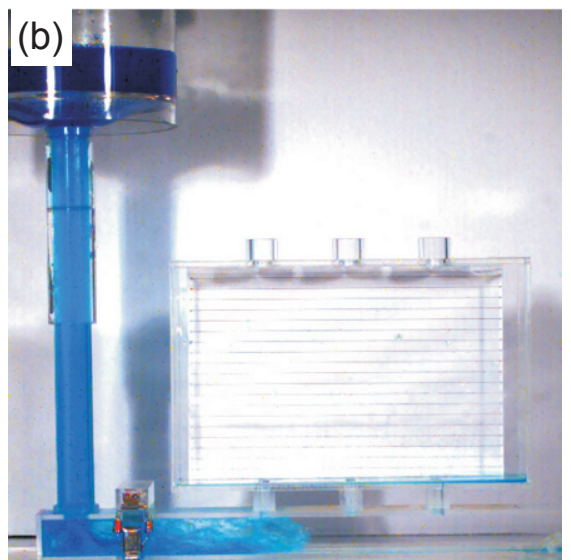

(b) $0.36 \mathrm{~s}$

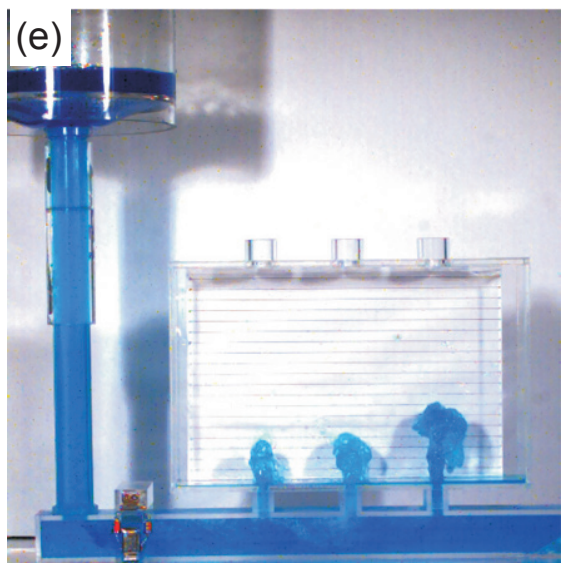

(e) $0.82 \mathrm{~s}$

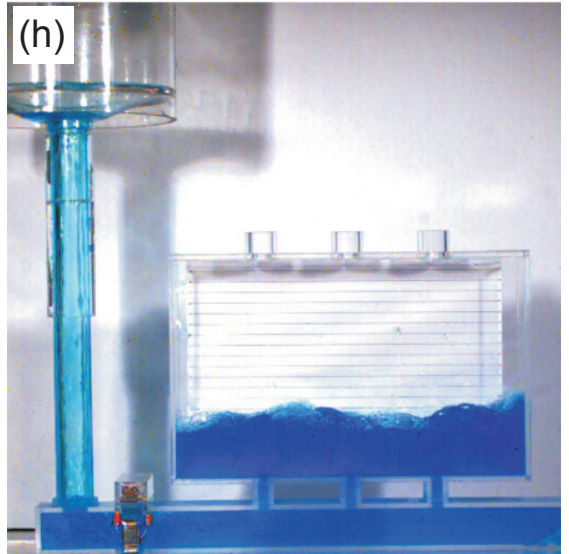

(h) $2.04 \mathrm{~s}$

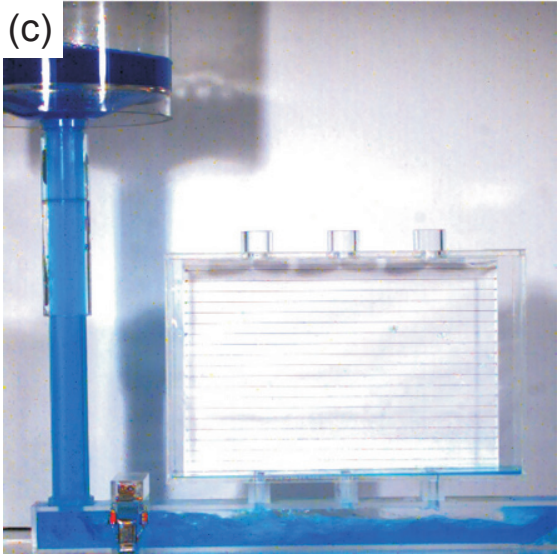

(c) $0.54 \mathrm{~s}$

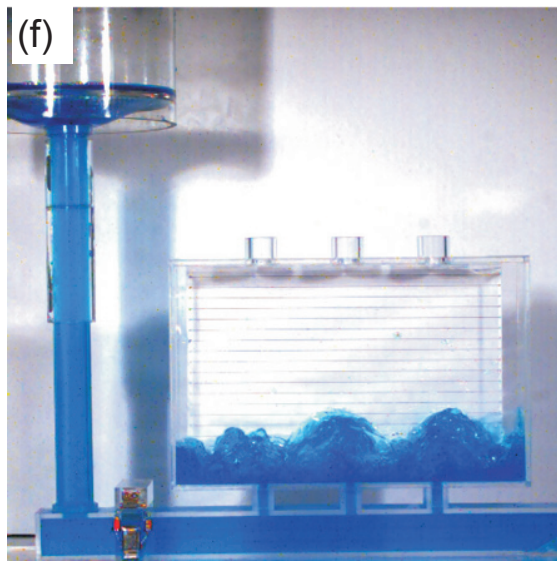

(f) $1.37 \mathrm{~s}$

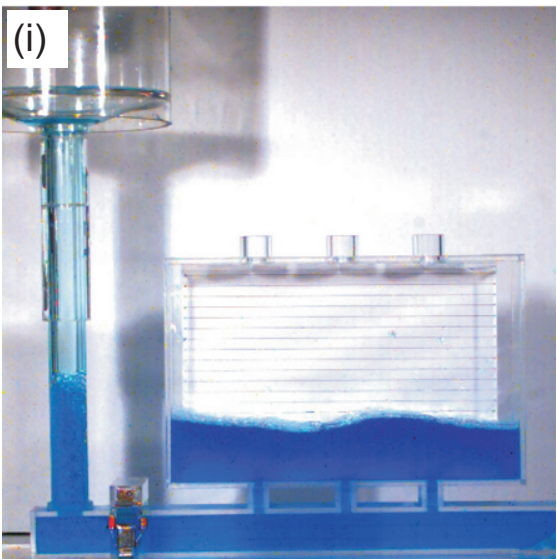

(i) $2.66 \mathrm{~s}$

Fig. 5: Water model experimental results of traditional gating system with an initial pouring volume of $1,600 \mathrm{ml}$

velocity in the runner. Accordingly, the experiments with larger quantities of water show high water jump height and large fluctuation of sloshing than the $1,600 \mathrm{ml}$ case in casting part and, as expected, the whole filling process takes longer. In the experimental results of the initial water volume of $2,800 \mathrm{ml}$, water jump height through the gate located at the end of the runner showed a large increase compared with other cases.

Figure 7 shows the water model experimental results with the irregular and regular filters when the initial water volume is $2,800 \mathrm{ml}$. As shown in the figure, even the 10 PPI filter which has the largest pore size is effective to decrease the flow velocity in the runner. While the experiment with 10 PPI and 20 PPI of irregular filter still shows a high flow velocity in the runner and high water jump height in the casting part, 30 PPI of irregular filter shows relatively decreased flow velocity and water jump height. Total filling time becomes longer in the higher PPI number filter and every experiment with a filter takes about $1.5 \mathrm{~s}$ longer than the experiment without a filter for the corresponding water quantity. The regular filter also shows laminar flow in the runner and decreased flow velocity and water jump height in the casting part. The effectiveness of flow velocity decrease and sloshing reduction in the casting part is weaker than that of irregular filters. Total filling time of every experiment is about $0.5 \mathrm{~s}$ longer than the experiment for the corresponding water quantity without a filter.

When the initial volume of water is $2,800 \mathrm{ml}$ in the traditional gating system, Fig. 8 shows the flow aspects of the experiments 


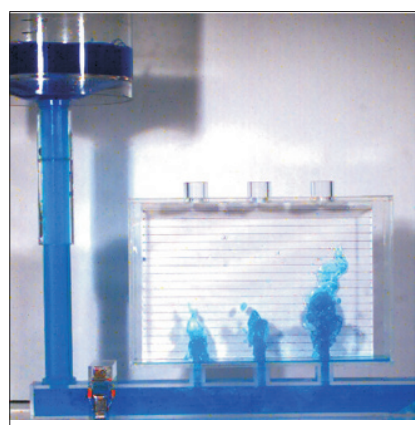

$0.82 \mathrm{~s}$

(a) $2000 \mathrm{ml}$

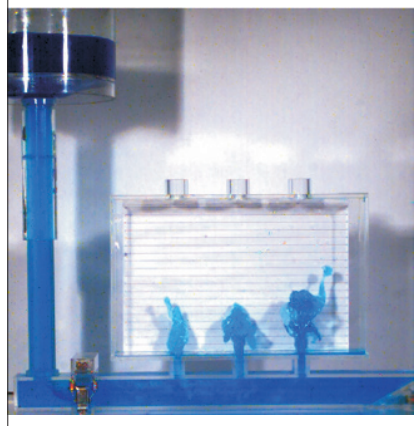

$0.82 \mathrm{~s}$

(b) $2400 \mathrm{ml}$

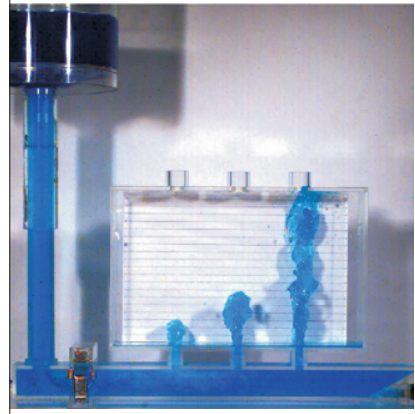

$0.79 \mathrm{~s}$

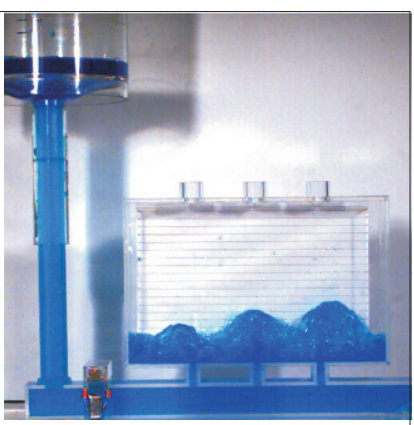

$1.32 \mathrm{~s}$

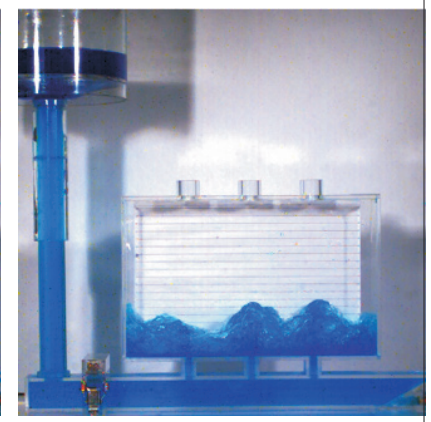

$1.36 \mathrm{~s}$

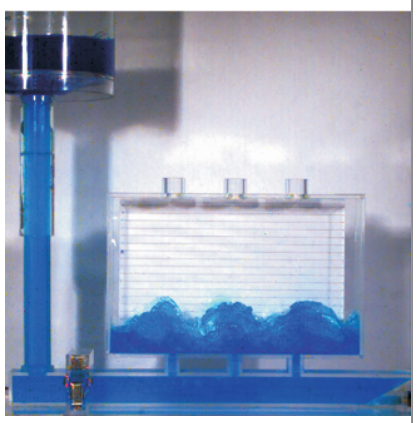

(c) $2800 \mathrm{~m}$

\section{Fig. 6: Water model experimental results of} traditional gating system with initial pouring volumes of $2000 \mathrm{ml}, 2400 \mathrm{ml}$, and $2800 \mathrm{ml}$

without filter and with a 10 PPI irregular foam filter. It can be seen that the flow pattern without filter, which was the worst, significantly improved just by the use of the 10 PPI irregular filter.

Figure 9 shows the graph of water jump height in the casting part. Water jump height of gates 1 and 3 shows tendency to increase as the initial water volume increases; conversely gate 2 shows a decreasing tendency. The flow rate through gate 2 is strongly influenced by gate 3 . As the flow rate through gate 3 increases, water volume flow through the gate 2 relatively decreases. Every case has a large variation between the maximum and minimum values. This means that the filling procedure is unstable in this gating system due to the turbulent flow in the runner. As a result, a lot of effort is required to remove defects generated during the filling process in the traditional gating system.

The flow aspect of every experiment with a ceramic foam filter improved in terms of flow stability. In the traditional gating system, even the 10 PPI irregular filter was effective to

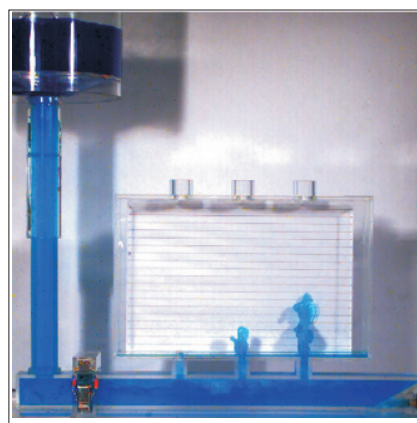

$0.90 \mathrm{~s}$

(a) $10 \mathrm{PPI}$ irregular

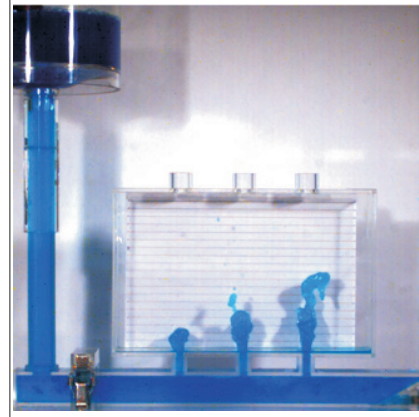

$0.92 \mathrm{~s}$

(b) 20 PPI irregular

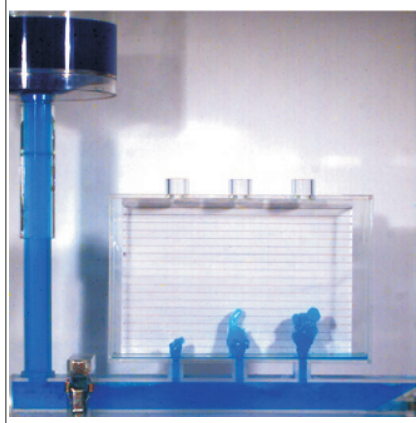

$1.02 \mathrm{~s}$

(c) $30 \mathrm{PPI}$ irregular

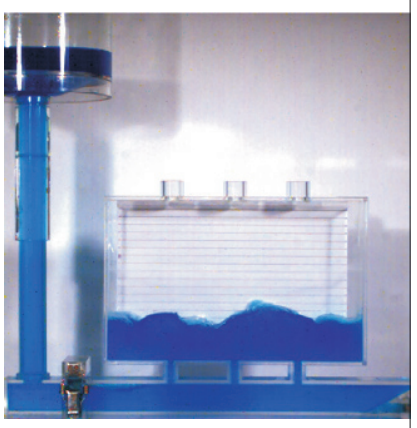

$2.49 \mathrm{~s}$

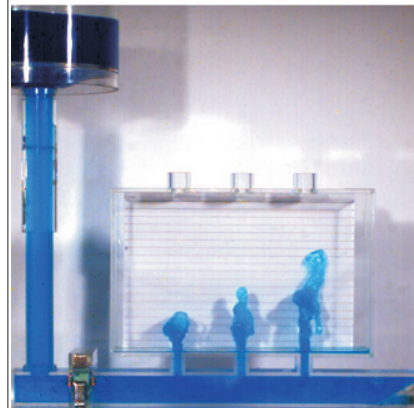

$0.88 \mathrm{~s}$

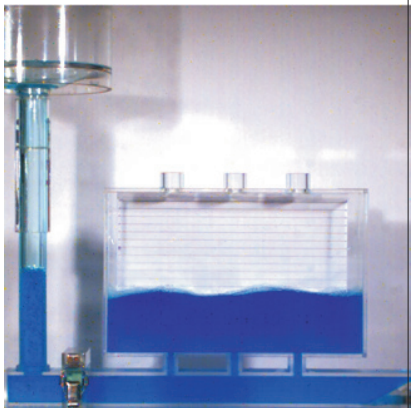

$3.30 \mathrm{~s}$ (d) 10 PPI regular

Fig. 7: Water model experimental resultsof traditional gating system with initial fluid volume of $2800 \mathrm{ml}$ according to different types of filters

reduce the bubble generation by reducing turbulent flow, but it is still difficult to confirm water flow is fully stabilized due to the variation of experiment result values as shown in Fig. 10(a). At higher PPI number filters such as 20 PPI and 30 PPI, the variation of experimental values is clearly lessened and presents steady experimental results as verified in Fig. 10 (b), (c). Even though the regular filter produces a marginally higher water jump height and variation than the same PPI number irregular filter, 


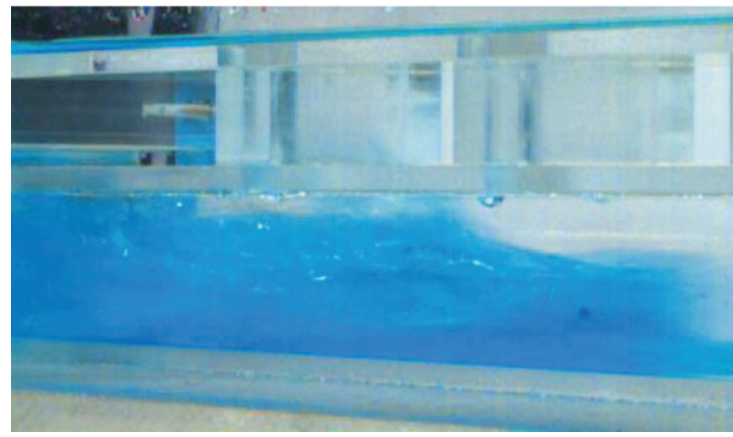

(a) Without filter

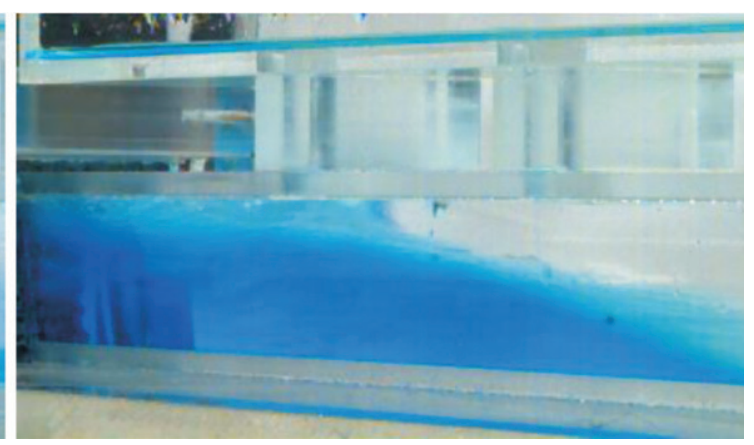

(b) With 10 PPI irregular filter

Fig. 8: Detail view of water model experimental result of traditional gating system at $0.5 \mathrm{~s}$

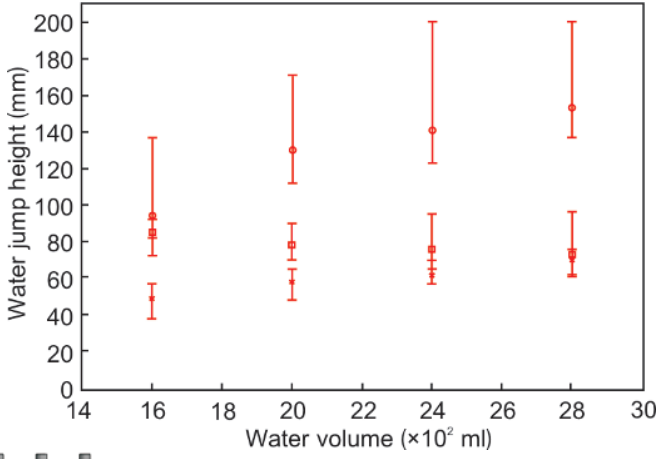

Cross: Gate 1

Square: Gate 2

Circle: Gate 3

Fig. 9: Water jump height of the traditional gating system

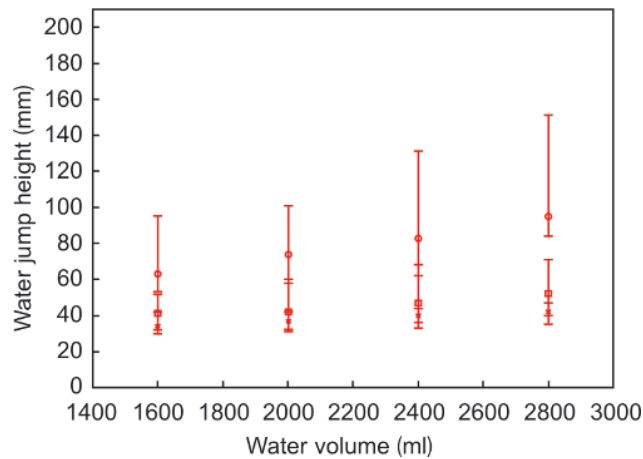

(a) Irregular $10 \mathrm{PPI}$

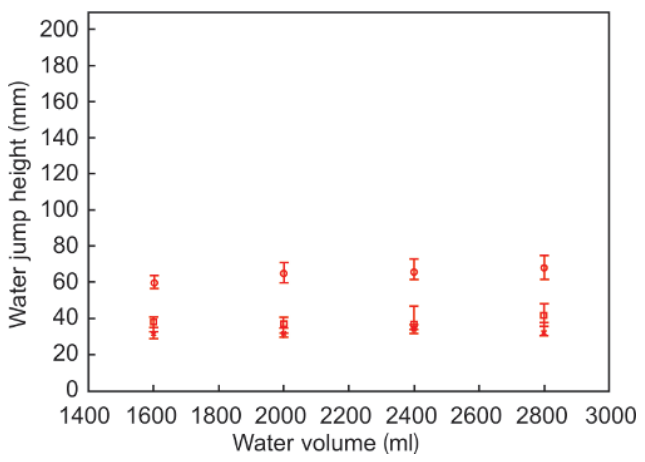

(c) Irregular $30 \mathrm{PPI}$ it shows similar performance. The experiment determined that there is a certain limit to improvement with only the ceramic foam filters.

\subsection{Flow adaptive gating system}

Water model experimental results from the initial water volume of 1,600 $\mathrm{ml}$ are shown in Fig. 11. After $0.24 \mathrm{~s}$ from the pouring start, falling water meets with the bottom of the runner. From $0.36 \mathrm{~s}$ to $0.80 \mathrm{~s}$, the water flows in a stable manner without any fluctuation due to the flat shape runner with a low height. Accordingly, there is no bubble generation in the runner. The water flow reaches the blind feeder that is located at the end of the runner in $0.8 \mathrm{~s}$. At $0.98 \mathrm{~s}$ and $1.16 \mathrm{~s}$, it is found that the water in the blind feeder does not flow to the upstream and it remains in the blind feeder. Next, the water flows into the casting part through the gate at $0.98 \mathrm{~s}$ and there is no water jump. Similarly

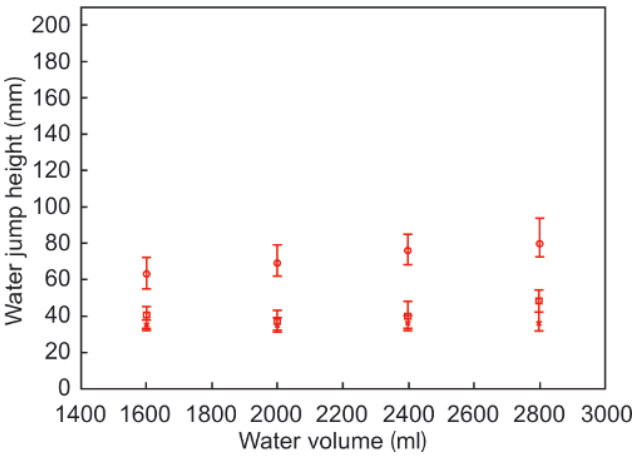

(b) Irregular $20 \mathrm{PPI}$

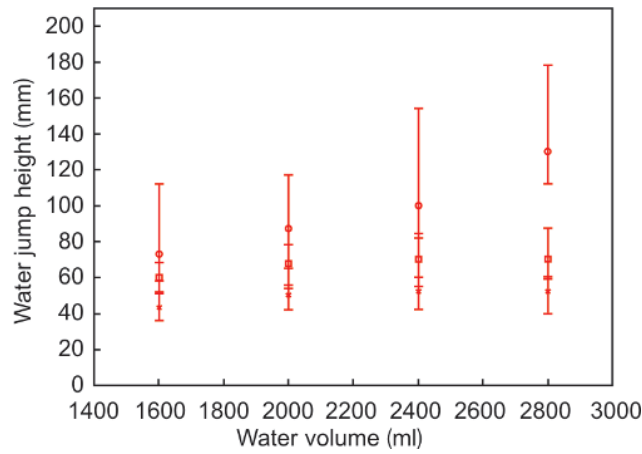

(d) Regular 10 PPI

Fig. 10: Water jump height of traditional gating system with different types of filters 


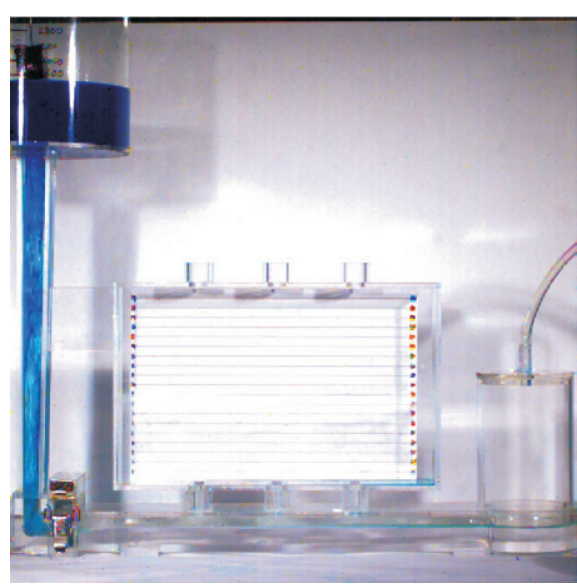

(a) $0.24 \mathrm{~s}$

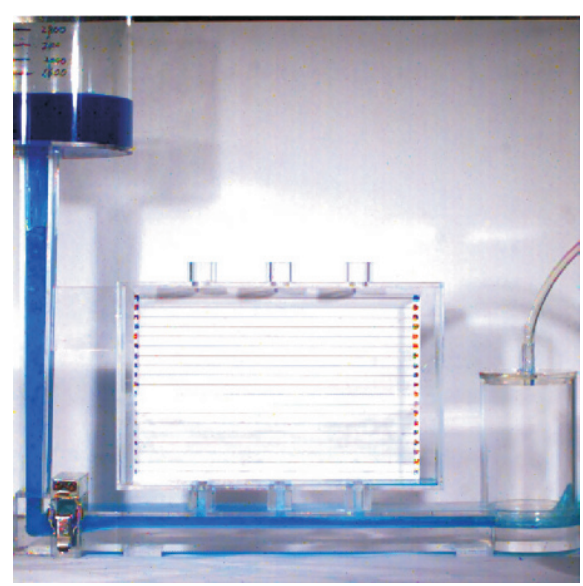

(d) $0.80 \mathrm{~s}$

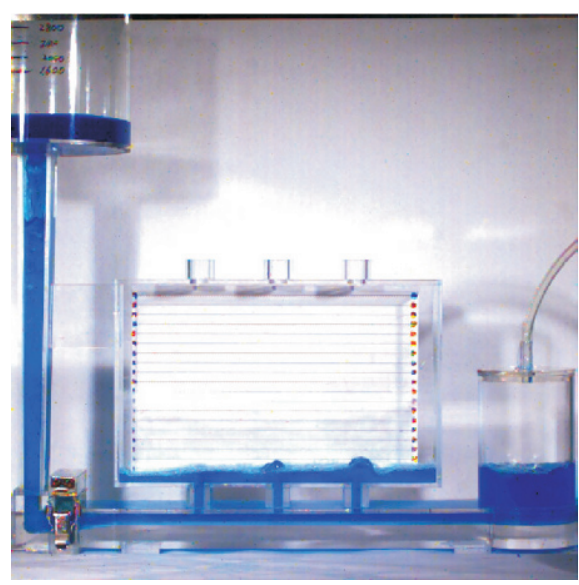

(g) $1.84 \mathrm{~s}$

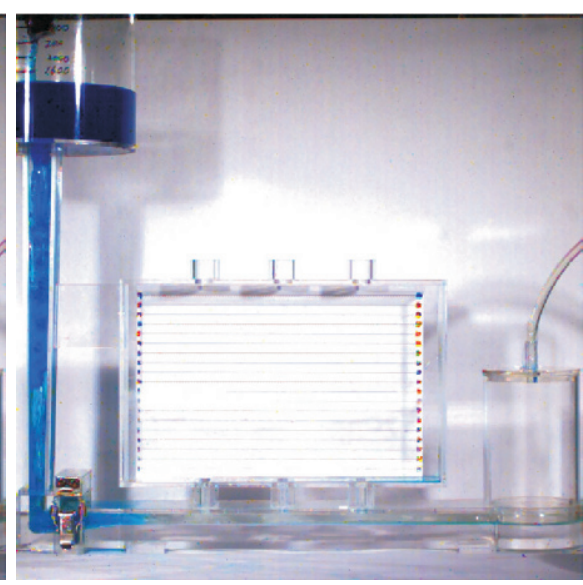

(b) $0.36 \mathrm{~s}$

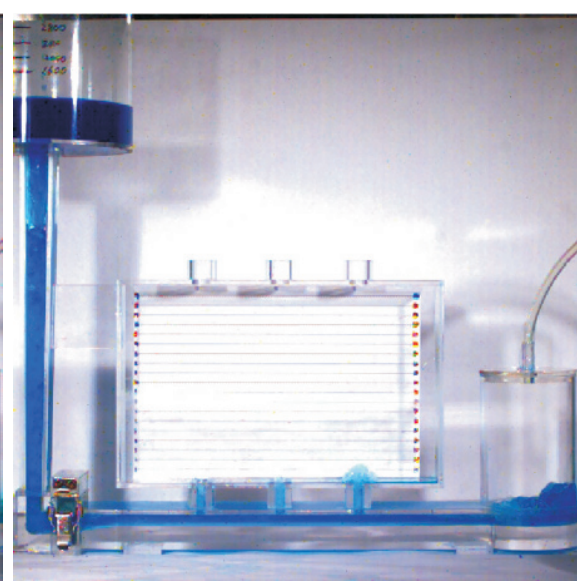

(e) $0.98 \mathrm{~s}$

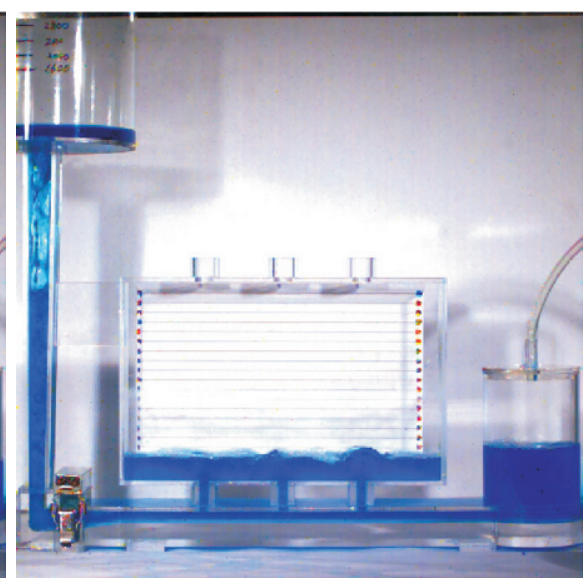

(h) $2.50 \mathrm{~s}$

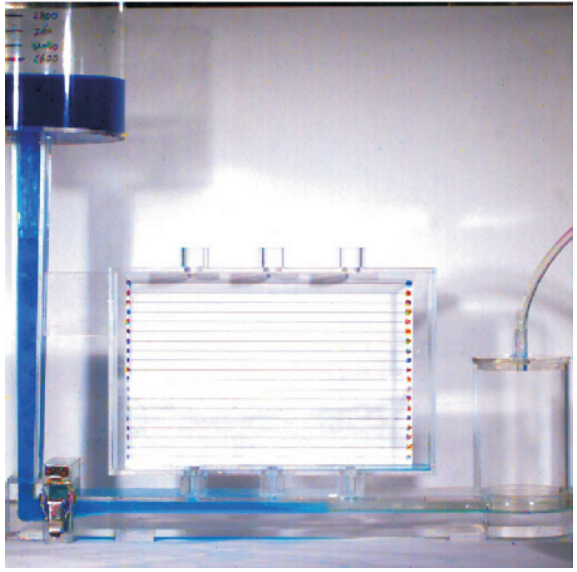

(c) $0.54 \mathrm{~s}$

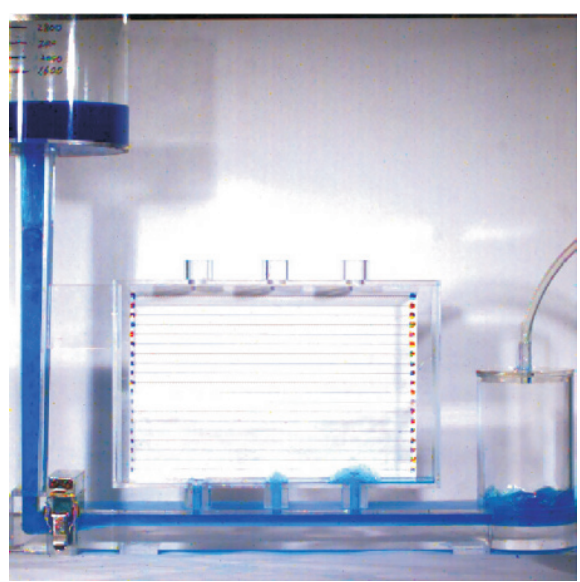

(f) $1.16 \mathrm{~s}$

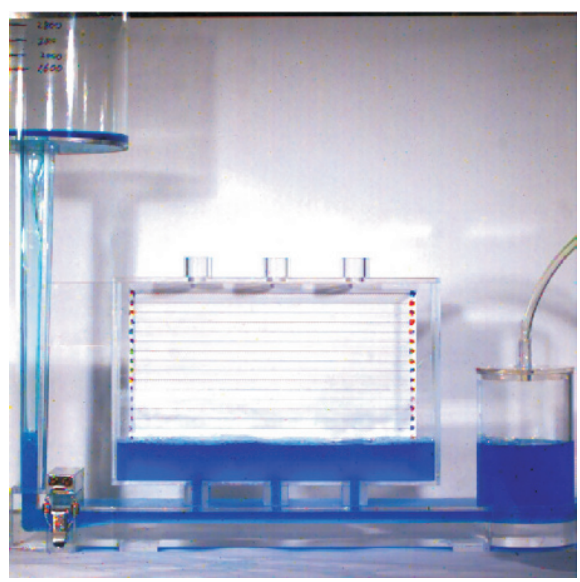

(i) $3.28 \mathrm{~s}$

Fig. 11: Water model experimental results of flow adaptive gating system with an initial pouring volume of $1600 \mathrm{ml}$

as in the traditional gating system, the casting part starts to be filled from the gate located at the end of the runner and is filled in the order of proximity to the end of the runner. The water passing the gate which is the nearest one from the end of the runner has the highest height, the water past the middle gate is the second highest, and the water past the gate which is the nearest one from down sprue has the lowest height. It is confirmed that the water jump height is clearly lower than that of the traditional gating system. Thereafter, it leads to weak sloshing in the casting part.

Experimental results for initial water volumes of 2,000 ml, 2,400 $\mathrm{ml}$ and 2,800 $\mathrm{ml}$ are shown in Fig. 12. Flow aspect is almost similar to that of the experiment with an initial water volume of 1,600 $\mathrm{ml}$. The velocities of water passing the runner increase as the initial volume of water reservoir increases, and water arrives at the casting part faster than in the experiments using 1,600 $\mathrm{ml}$. For the 1,600 $\mathrm{ml}$ experiment, the water velocity was not high enough to make the water jump in the casting part. However, in the cases of 2,000 ml, 2,400 $\mathrm{ml}$ and $2,800 \mathrm{ml}$, water jump height is certainly high. The water jump height in the casting part becomes higher as the initial water volume increases, but there is no remarkable difference above the volume of $2,400 \mathrm{ml}$. 

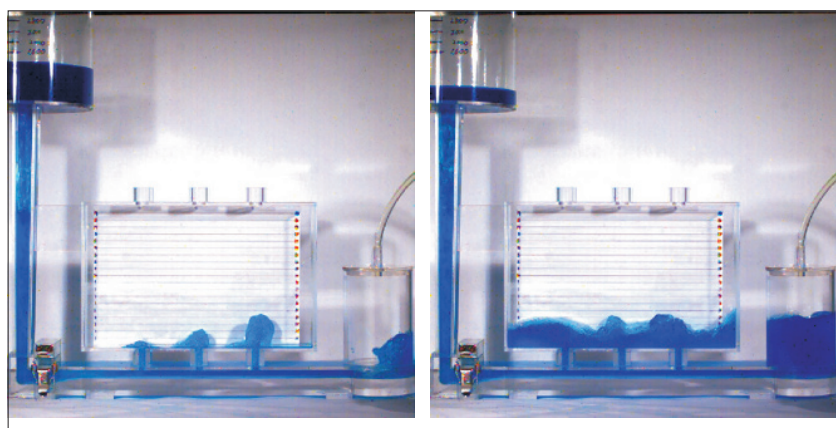

(a) $2000 \mathrm{ml}$

$1.82 \mathrm{~s}$

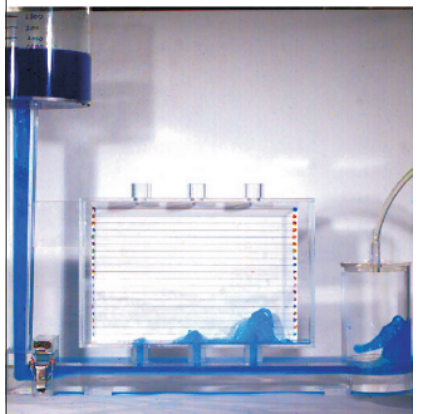

$0.84 \mathrm{~s}$

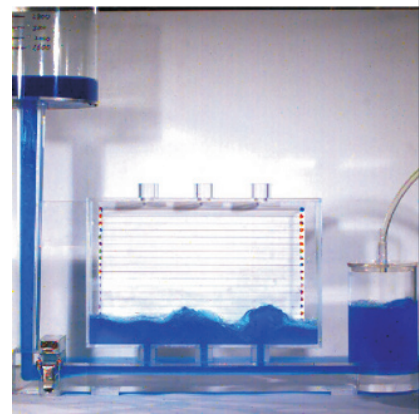

(b) $2400 \mathrm{ml}$

$1.83 \mathrm{~s}$

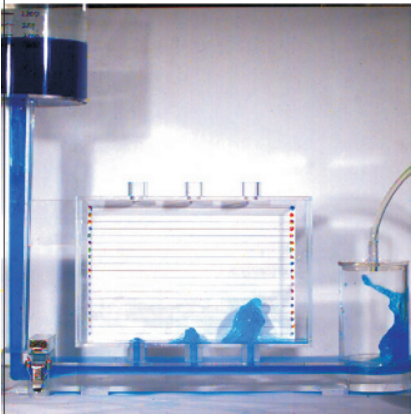

$0.78 \mathrm{~s}$

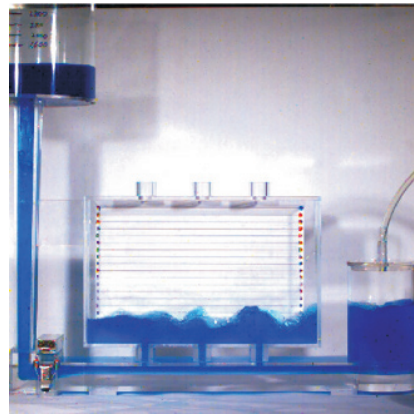

$1.77 \mathrm{~s}$ (c) $2800 \mathrm{ml}$

Fig. 12: Water model experimental resultsof flow adaptive gating system with initial pouring volumes of $2000 \mathrm{ml}, 2400 \mathrm{ml}$, and $2800 \mathrm{ml}$

Figure 13 provides the water model experimental results applying the filter, with an initial water volume of $2,800 \mathrm{ml}$. In the flow adaptive gating system, every case shows nearly the same flow pattern from 10 PPI to 30 PPI irregular filters. Water flows into the casting part in a stable manner without water jump. Thus, the water injected into the casting part moves upward quietly and there is no sloshing until filling ends. The time for the whole filling procedure takes about $0.7-1.0 \mathrm{~s}$ longer than in the case of without the filter. In the flow adaptive gating system, the regular filter also serves effectively to prevent sloshing by reduction of flow velocity and water jump in the casting part. Although there is a little water jump from the water passing through the rightmost gate, its height is relatively negligible, and it did not appear as a sloshing of the free surface.

When the initial volume of water is $2,800 \mathrm{ml}$ in the flow adaptive gating system, Fig. 14 shows the flow aspects of the experiment without filter and with 10 PPI irregular foam filter. When the filter is not inserted, it can be seen that the fluid

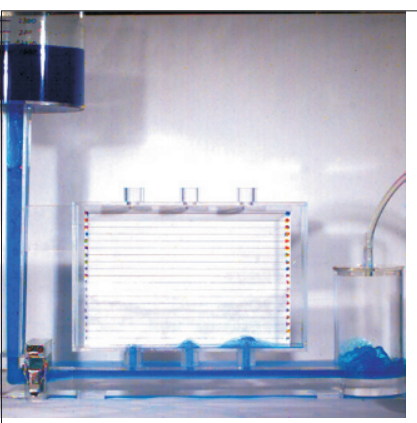

$0.88 \mathrm{~s}$

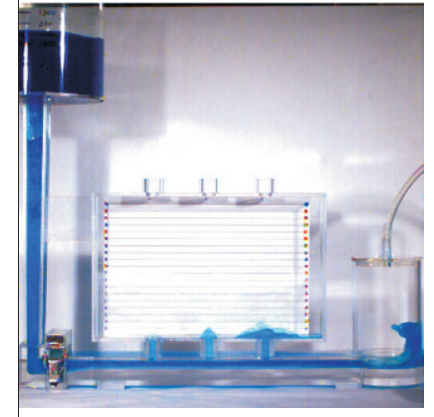

$0.94 \mathrm{~s}$

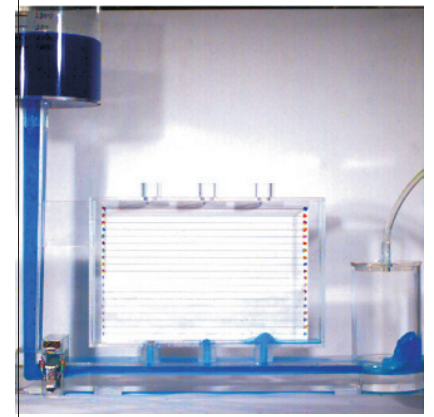

$1.09 \mathrm{~s}$

(c) $30 \mathrm{PPI}$ irregular

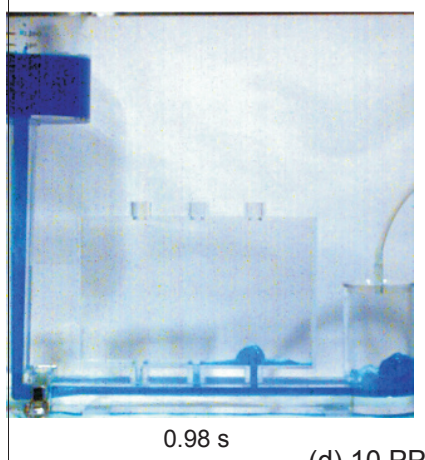

(d) $10 \mathrm{PPI}$ regular

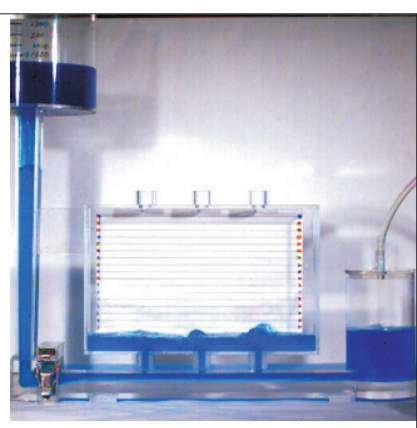

$2.17 \mathrm{~s}$

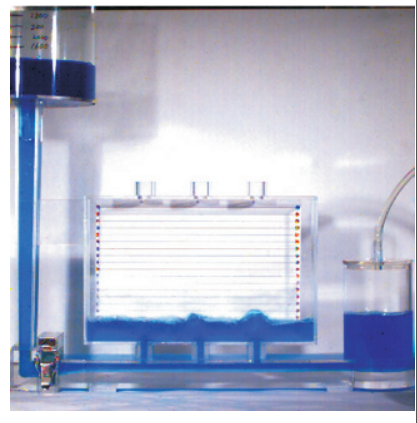

$2.40 \mathrm{~s}$

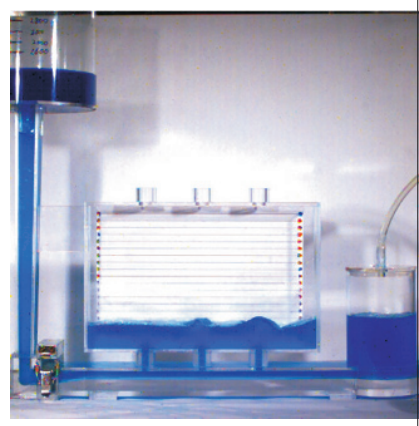

$2.80 \mathrm{~s}$

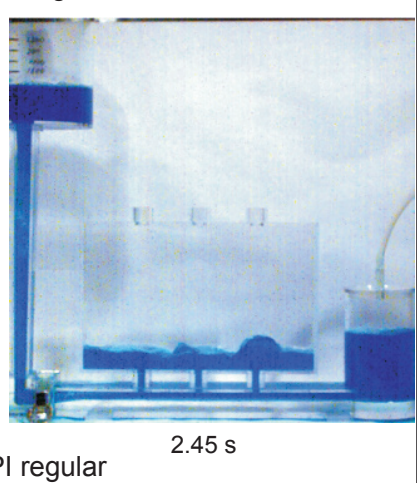

Fig. 13: Water model experimental results of flow adaptive gating system with an initial fluid volume of $2800 \mathrm{ml}$ with different types of filters

flows in a state of almost filling the runner cross-section. It was confirmed just some air is flowing with water. It can be seen that the flow pattern also can be improved just by the use of the 10 PPI irregular filter.

Figure 15 is the graph of water jump height in the casting part. Water jump height and variation between the maximum and minimum values of all gates tend to increase as the initial water volume increases. Both water jump height and variation are 


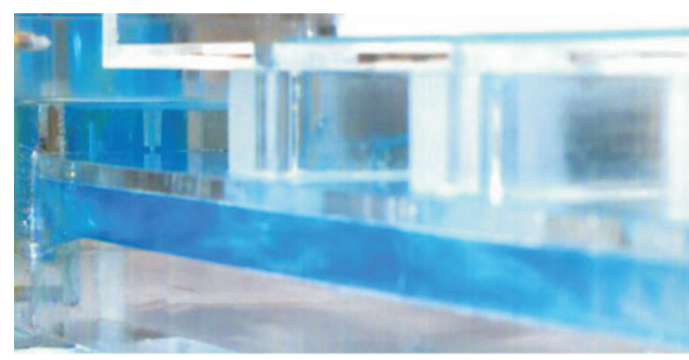

(a) Without filter

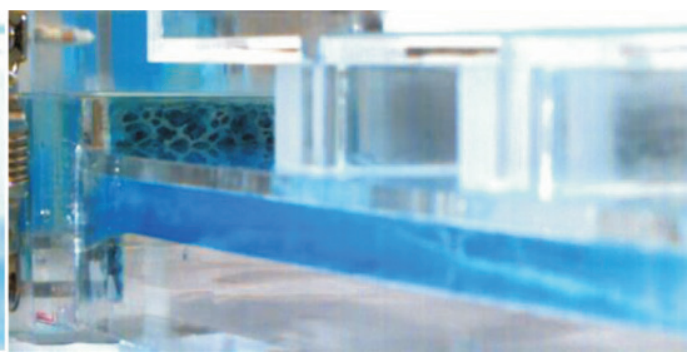

(b) With a $10 \mathrm{PPI}$ irregular filter

Fig. 14: Detail view of water model experimental result of flow adaptive gating system at $0.9 \mathrm{~s}$

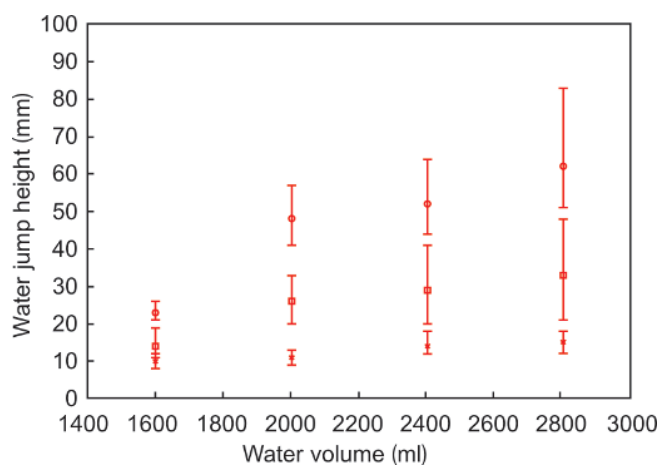

Cross: Gate 1

Square: Gate 2

Circle: Gate 3

Fig. 15: Water jump height of flow adaptive gating system

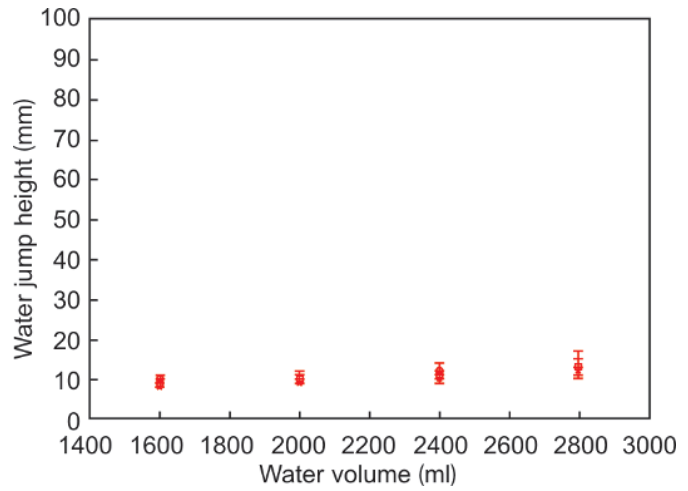

(a) Irregular 10PP I

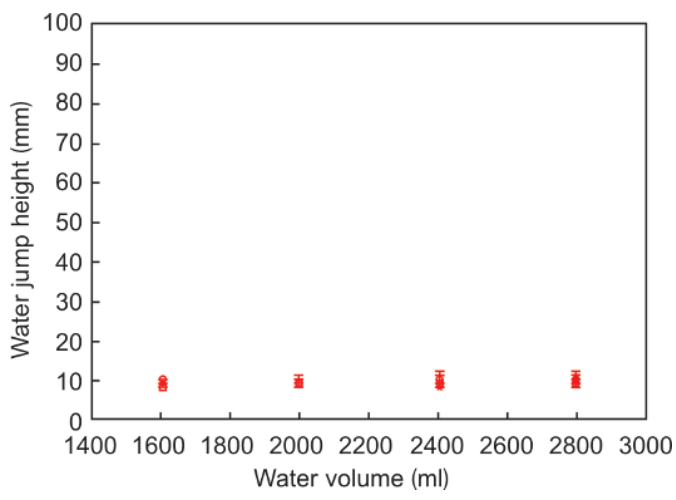

(c) Irregular 30PPI much smaller than that of the traditional gating system. Thus, the flow adaptive gating system appears to significantly lessen the defects related to bubbles and oxide inclusions and stabilize the water flow. However, the variation becomes larger as the initial water volume increases and this means that the flow adaptive gating system can produce unstable flow beyond a certain value of velocity.

In the flow adaptive gating system, even the 10 PPI irregular filter can stabilize water flow at initial water volume of $2,800 \mathrm{ml}$. As shown in Fig. 16, water jump heights of all gates are almost the same and have a slight variation regardless of initial water volume and PPI value of the filter. Although the regular filter in the flow adaptive gating system also shows a large decrease of water jump height and variation, it is less effective than the same PPI number of an irregular filter.

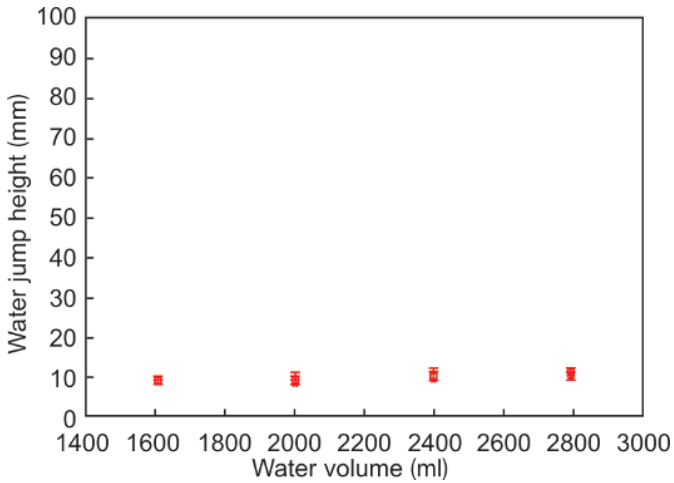

(b) Irregular 20PPI

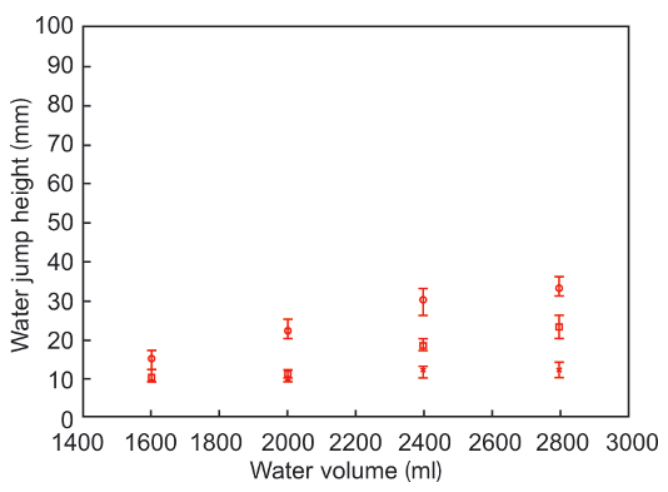

(d) Regular 10PPI

Fig. 16: Water jump height of flow adaptive gating system with different types of filters 


\section{Conclusions}

In this study, the water model experiment was used to identify the casting defects that occur frequently in the molten metal filling process during the casting process. In the case of the traditional gating system, the air bubbles generated in the swirls occurring within the runner and imported from free falling water in the sprue flow with the water stream into the casting through the gate. If such bubbles remain in the inside of the product during the solidification process, it could evolve as air porosity. Additionally, repeated experiments showed large differences in the velocity of flow through the gate. These differences can cause quality variations of casting in the actual casting process. Backflow induced from changing the flow direction at the end of the runner can break the oxidized layers on the molten metal surface and thereby cause oxide inclusion defects in the actual casting process.

The flow adaptive gating system that is devised to reduce the casting defects caused by the flow of molten metal in the traditional gating system showed improved flow patterns. It altered the turbulent flow into laminar flow by forming a proper cross-section of runner and prevented the double oxide phenomenon by grasping the backflow in the blind feeder. Although the flow adaptive gating system is free of defects related to bubbles and oxide inclusions, the great sloshing of the free surface resulting from high velocity at the gate can generate air bubbles in the casting part and be another source of oxide inclusions and bubble defects in casting.

The use of the filter was found to convert the flow pattern of water in the desired direction. The ceramic foam filter performed well to reduce flow velocity and stabilize the water stream. The flow pattern without a filter can be improved significantly even with the the use of just a 10 PPI irregular filter. However, there is a certain limitation to improvement by only the use of a ceramic foam filter because the filter cannot resolve all the problems caused by a poorly designed gating system. As it was identified in the results of the flow adaptive gating system, a well-designed gating system accompanied with a ceramic foam filter represented the most stable flow aspect.

\section{References}

[1] Campbell J. Invisible Macrodefects in Castings. Journal de Physique IV, 1993, 03(C7): C7861-C7872.

[2] Laslaz G and Laty P. Gas Porosity and Metal Cleanliness in Aluminum Casting Alloys. AFS Transactions, 1991, 99: 83-90.

[3] Divandari M. Mechanisms of Bubble Damage in Castings. Ph.D thesis, The University of Birmingham, UK, 2001.
[4] Reilly C, Green N R, and Jolly M R. Oxide Entrainment Structures in Horizontal Running Systems. Shape Casting Symposium, San Francisco, USA, 2009.

[5] Bonollo F and Odorizzi S. Numerical Simulation of Foundry Processes. Servizi Grafici Editoriali, Padova, Italy, 2001.

[6] Liu L, Samuel A M, and Samuel F H. Influence of Oxides on Porosity Formation in Sr-treated Al-Si Casting Alloys. Journal of Material Science, 2003, 38(6): 1255-1267.

[7] Kuriyama Y, Yano K and Nishido S. Optimization of Pouring Velocity for Aluminum Gravity Casting. Fluid Dynamics, Computational Modeling and Applications, 2012, 26, Dr. L. Hector Juarez (Ed.), Japan.

[8] Masoumi M, Hu H, Hedjazi J, et al. Effect of Gating Design on Mold Filling. AFS Transactions, 2005, Paper 05-152(02).

[9] Hsu Fu-Yuan, Jolly M R and Campbell J. A Multiple-Gate Runner System for Gravity Casting. Materials Processing Technology, 2009, 209(17): 5736-5750.

[10] Campbell J. Castings. 2nd ed., Butterworth-Heinemann, Oxford, 2003.

[11] Campbell J. Castings Practice the 10 Rules of Castings. Modern Castings Elsevier Butterworth-Heinemann, 2004, 44: 39-40.

[12] Svoboda J M. Basic Principles of Gating and Risering. American Foundry Men's Society Cast Metals Institute AFS-CMI, 1995

[13] Ricardo Fuoco. The Effect of Gating System Design on the quality of Aluminum Gravity Casting. Computational Materials Science, 2006, 36(4): 457-467.

[14] Bao S, Engh T A, Syvertsen M. Inclusion (particle) removal by interception and gravity in ceramic foam filters. Journal of Materials Science, 2014, 47(23): 7986-7998.

[15] Fuwang Chen, Xuebing Huang and Yong Wang. Investigation on foam ceramic filter to remove inclusions in revert superalloy. Materials Letters, 1998, 34: 372-376.

[16] Jonas B, Svensson I L, and Yasuhiro M. Evaluation of Filter Parameters from Direct Observations of Metal Flow in Aluminium Castings. In: Proc. 1st International Conference on Gating, Filling and Feeding of Aluminum Castings, 1999.

[17] Hatef H, Ramin R. Naturally-Pressurized Running Systems: The Role of Ceramic Filters. Journal of Applied Sciences, 2009, 9(1): 2115-2122.

[18] Roger S K. The use of foam filters to improve production control in the aluminium automotive foundry. In: Proc. 1st International Conference on Gating, Filling and Feeding of Aluminum Castings, 1999.

[19] Hadi A, Baghshahi S, Emadi R. Different pore size alumina foams and study of their physical and mechanical properties. Mater. Sci. Eng., 2009, 132: 340-343.

[20] Yury Lerner. Development of an improved direct pour system for aluminum casting. In: Proc. 1st International Conference on Gating, Filling and Feeding of Aluminum Castings, 1999.

[21] Moreira E A, Innocentini M D M, Coury J R. Permeability of ceramic foams to compressible and incompressible flow. Journal of the European Ceramic Society, 2004, 24: 3209-3218.

[22] Kennedy M W, Zhang K X, Fritzsch R. Characterization of Ceramic Foam Filters Used for Liquid Metal Filtration. Metallurgical and Materials Transactions B, 2013, 44(3): 671-690. 